\title{
Focalização isoelétrica na identificação das hemoglobinas
}

\author{
The isoelectric focusing for hemoglobin identification
}

Luciane Cristina Bertholo'; Haroldo Wilson Moreira²

\begin{abstract}
unitermos resumo
Focalização isoelétrica

Introdução: Considerando a significativa freqüência das hemoglobinopatias na população brasileira Hemoglobinopatias

Diagnóstico laboratorial e a necessidade do estabelecimento de metodologia confiável, rápida, reprodutível e possível de ser aplicada a um grande número de amostras, foi objetivo desse trabalho analisar as diferenças observadas pelas metodologias eletroforéticas em acetato de celulose e em ágar amido em comparação com a focalização isoelétrica (IEF) e o estabelecimento de um padrão amostral apresentando as principais posições das hemoglobinas anormais, com enfoque nas observadas na população brasileira. Casuística e métodos: O material de estudo foi constituído por amostras de sangue de pacientes laboratoriais e doadores pertencentes à região central do estado de São Paulo, Brasil, e nelas aplicamos os testes de rotina laboratorial. Para efeito de comparação e validade das provas laboratoriais, correlacionamos os resultados dos testes com a técnica de focalização isoelétrica. Resultados e discussão: Os resultados observados em cada procedimento, somados aos dados de literatura, permitiram estabelecer padrões de migração para cada sistema eletroforético das hemoglobinas observadas na população brasileira. Dessa forma foram estruturados quadros com a possibilidade do uso dos mesmos evidenciando a facilidade e a viabilidade dessa técnica por diferentes laboratórios.
\end{abstract}

abstract

Background: Considering the significant frequency of hemoglobinopathies in the Brazilian population and the necessity of establishing a reliable methodology, quick, reproductive and possible to be applied in a large number of samples, it was the objective of this work to analyze the differences on electrophoretic procedures with cellulose acetate and acid agar compared with isoelectric focusing (IEF), and to establish a standard of migration, presenting main positions of abnormal hemoglobin, based on Brazilian population hemoglobin. Material and method: The studied material was formed by blood samples from laboratory patients and blood donors of São Paulo state central area, Brazil, and applied laboratory routines tests. For a reasonable comparison and validation of laboratory tests, we related the results with isoelectric focusing. Results and discussion: These observations added to literature accounts allowed the establishment of standards of migration all over hemoglobinopathies observed in the Brazilian population. In this way, charts were developed to demonstrate the simplicity and viability of this techinique by different laboratories. key words Isoelectric focusing Hemoglobinopathies Laboratories diagnostic

\footnotetext{
1. Mestra em Análises Clínicas pela Faculdade de Ciências Farmacêuticas da Universidade Estadual Paulista (FCF/UNESP); professora-assistente da Universidade Regional do Noroeste do Estado do Rio Grande do Sul (UNIJUI).

2. Professor-titular do Departamento de Análises Clínicas da FCF/UNESP.

Trabalho realizado no Laboratório da Disciplina de Hematologia Clínica da FCF/UNESP. Dissertação apresentada para obtenção do grau de mestre em Análises Clínicas, área de Concentração em Análises Clínicas da FCF/UNESP, em 2001.
} 


\section{Introdução}

As hemoglobinopatias constituem um grupo de alterações hereditárias prevalentes em muitas regiões do mundo, sendo decorrentes de alterações em genes estruturais, responsáveis pelo aparecimento das hemoglobinas variantes ou alterações em genes reguladores, resultando nas talassemias ${ }^{(11)}$.

A freqüência das hemoglobinopatias observadas numa população varia na dependência dos grupos raciais que originalmente colonizaram a região analisada e, mesmo numa região específica, sabemos que essa freqüência pode variar, dependendo do grupo que se analisa na população escolhida, principalmente ao se separar os grupos caucasóides e não-caucasóides ${ }^{(9)}$.

A formação da população brasileira teve influência inicial dos nativos, dos colonizadores portugueses e dos escravos africanos, sendo que mais tarde sofreu maciça contribuição de povos europeus e asiáticos, principalmente de italianos, espanhóis, alemães e japoneses.

O Brasil tem dimensões continentais, com aproximadamente 8,5 milhões de $\mathrm{km}^{2}$, sendo composto por 26 estados e o Distrito Federal, sede do governo federal. Sua população apresenta perto de 169 milhões de habitantes distribuídos em $54 \%$ de brancos, $39,5 \%$ de mestiços, $5,7 \%$ de negros, $0,6 \%$ de asiáticos e $0,2 \%$ de indígenas americanos ${ }^{(5)}$.

O estado de São Paulo, localizado na região Sudeste do Brasil, é o mais rico do país, o que propiciou, com o passar do tempo, uma crescente e contínua migração de populações de outros estados em busca de melhores condições de vida. Além disso, de 1827 a 1932 recebeu 2,6 milhões de migrantes, sendo $36 \%$ de italianos, $15 \%$ de portugueses, $14 \%$ de espanhóis, $4 \%$ de japoneses, $20 \%$ de alemães, árabes, austríacos, russos e poloneses e $11 \%$ de povos de outros países ${ }^{(7,8)}$. São Paulo, uma cidade cosmopolita, capital do estado de mesmo nome, tem mais de 10 milhões de habitantes ${ }^{(5)}$.

Esse intenso fluxo populacional, a miscigenação entre os povos e os diferentes padrões genéticos referentes ao polimorfismo das hemoglobinas propiciaram, no decorrer das gerações, o aparecimento de inúmeras hemoglobinopatias. O estado de homozigose, via de regra, desaparecia por causa de sua gravidade, preservando os heterozigotos que apresentavam formas mais brandas da doença, denominadas de traço ou estigma, com a possibilidade de deixar descendentes, mantendo, deste modo, o gene na população.

Essas patologias podem ser identificadas por procedimentos eletroforéticos, mais comumente pelas eletroforeses em acetato de celulose alcalina, em ágar ácido, e menos freqüentemente pela focalização isoelétrica em gel de poliacrilamida ou em agarose em diferentes

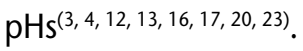

Estudos populacionais realizados em várias regiões de nosso país demonstraram porcentagens que variam entre $0,1 \%$ a $1 \%$ para as hemoglobinas menos freqüentes e para aquelas com padrão homozigótico e de 1,5\% a 10\% para as consideradas heterozigóticas, quer sejam hemoglobinas

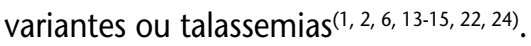

Considerando-se a freqüência das hemoglobinopatias na população brasileira e a necessidade do estabelecimento de metodologia confiável, rápida, reprodutível e possível de ser aplicada a um grande número de amostras quando em estudos populacionais, foi objetivo desse trabalho analisar as diferenças observadas pelas metodologias eletroforéticas em acetato de celulose e em ágar amido, em comparação com a focalização isoelétrica (IEF) e o estabelecimento de um padrão amostral a ser utilizado nesse sistema apresentando as principais posições das hemoglobinas anormais, com enfoque naquelas observadas na população brasileira.

\section{Casuística e métodos}

O material de estudo foi constituído por 8.351 amostras de sangue, sendo 6.271 de pacientes laboratoriais e 2.080 de doadores de sangue, todos pertencentes à região central do estado de São Paulo, Brasil. Amostras não usualmente detectadas em nossa região e que tínhamos o interesse de acrescentar ao nosso estudo foram obtidas em outros laboratórios que se ocupam dessa identificação.

Nessas amostras aplicamos os testes da rotina laboratorial na caracterização de hemoglobinopatias, a saber: eletroforese qualitativa e quantitativa em $\mathrm{pH}$ alcalino ${ }^{(12)}$ e eletroforese qualitativa em $\mathrm{pH}$ ácido ${ }^{(23)}$. Para efeito de comparação e validade das provas laboratoriais e de nossos objetivos, associamos a esses testes a técnica de focalização isoelétrica ${ }^{(13,16,17,20)}$.

Para essa última, o hemolisado obtido de sangue total colhido com anticoagulante não foi processado com solventes orgânicos, do tipo clorofórmio, pois este pode precipitar algumas hemoglobinas (incluindo a hemoglobina Bart's) e cadeias alfa livres, o que poderia propiciar a não-identificação de algumas hemoglobinas anormais. Deste modo, o mesmo era obtido com solução de cianeto de potássio a 0,05\%, fazendo-se uma diluição de $4 \mu \mathrm{l}$ da papa de hemácias em $25 \mu$ l de solução de cianeto de potássio a 0,05\%. 
A focalização isoelétrica foi realizada num aparelho Multiphor LKB em gel de poliacrilamida a 20\% contendo uma mistura de anfólitos com pH 6-8 e pH 7-9, sendo a polimerização estabelecida pela adição de persulfato de amônio e $\mathrm{N}, \mathrm{N}, \mathrm{N}^{\prime}, \mathrm{N}^{\prime}$-tetrametiletilenediamina (TEMED). A migração foi processada com uma tensão de 1.500 volts e corrente de $20 \mathrm{~mA}$ para um gel de $260 \times 125 \times 0,5 \mathrm{~mm}$. Após a migração, as frações foram fixadas com ácido tricloroacético a $20 \%$ por 5 a 10 minutos.

O presente trabalho foi desenvolvido cumprindo-se os princípios éticos estabelecidos na Resolução 196/96 do Conselho Nacional de Saúde (CNS).

\section{Resultados e discussão}

Como a população brasileira apresenta um alto grau de mistura racial devido à imigração dos colonizadores e posteriormente de outros povos, os resultados observados em cada procedimento, somados aos dados da literatura, permitiram estabelecer padrões de migração para cada sistema e válidos para amostras possíveis de serem observadas na nossa população. Dessa forma foram estruturadas as Figuras 1 e 2, onde apresentamos as posições das bandas das mutações variantes de cadeia beta, instáveis beta, variantes delta, variantes alfa, instáveis alfa e talassemias dos tipos beta, alfa e delta-beta, em eletroforese em acetato de celulose, em ágar ácido e em focalização isoelétrica.

A identificação dos fenótipos das hemoglobinas normais e anormais tem sido realizada rotineiramente por procedimentos eletroforéticos, utilizando-se como suporte 0 acetato de celulose em $\mathrm{pH}$ alcalino. A essa metodologia alguns raros laboratórios associam outros sistemas em diferentes suportes, como géis constituídos por ágar, agarose ou uma mistura de ágar-amido em $\mathrm{pH}$ ácido, alcalino, ou até mesmo neutro.

As análises laboratoriais têm mostrado que as metodologias utilizadas na rotina para a identificação das hemoglobinopatias nem sempre apresentam a resolução necessária para as perfeitas visualização e caracterização de algumas frações, como aquelas com concentrações inferiores a 1\%; frações que migram na mesma posição, quer seja em pH alcalino, quer em pH ácido; frações de hemoglobinas instáveis que se desnaturam pelos métodos usuais de obtenção do hemolisado com solventes orgânicos; frações que, em recém-nascidos, apresentam concentrações ínfimas e de difícil visualização; e frações de mutantes de cadeia alfa que migram de forma rápida, o que pode prejudicar a observação e, conseqüentemente, o correto auxílio diagnóstico.
A eletroforese que utiliza como suporte o ágar em $\mathrm{pH}$ ácido ou procedimentos assemelhados tem sido realizada apenas em alguns laboratórios e na diferenciação de hemoglobinas que migram na mesma posição em $\mathrm{pH}$ alcalino, como é o caso das hemoglobinas $S$ e $D$ e das $\mathrm{C}$ e $\mathrm{E}$. Entretanto, na população brasileira, são mais freqüentes as hemoglobinas $S$ e $C^{(1,14,24,25)}$, o que, de uma forma errônea, faz pensar que esse teste não apresenta a validade devida no auxílio diagnóstico laboratorial.

Por sua vez, a técnica da focalização isoelétrica fica na dependência da possibilidade do laboratório em realizar, com segurança, um procedimento que utiliza alta voltagem. Quando possível, essa técnica mostrou ser de fáceis realização e interpretação e com resolução capaz de diferenciar as bandas de cada fenótipo de hemoglobina $(\mathrm{Hb})$ na dependência do ponto isoelétrico (pl) de cada fração, sendo portanto particular e específica. O procedimento representa uma técnica na qual compostos eletroforéticos são fracionados de acordo com os seus pls através de um gradiente de $\mathrm{pH}$ contínuo ${ }^{(10,20)}$. Contrário à eletroforese de zona, na qual um $\mathrm{pH}$ constante do meio de separação estabelece uma densidade de carga constante na superfície da molécula, permitindo uma migração com mobilidade também constante, a carga do composto anfotérico na IEF permanece alterada e diminuindo de acordo com sua curva de titulação, em que ela migra através do gradiente de $\mathrm{pH}$, alcançando sua posição de equilíbrio, ou seja, a região onde o pH iguala-se ao seu pl, estabelecendo a parada da fração analisada ${ }^{(18,20,21)}$.

A utilização desse procedimento em triagens de hemoglobinas anormais demonstra ótima resolução, nítida separação das bandas de $\mathrm{HbA}$ e HbF e identificação de hemoglobinas variantes e frações menores, como a $\mathrm{HbA}_{2}$. Em casos onde frações anormais estão presentes em pequenas quantidades e em sangue de cordão, esta técnica também é muito empregada ${ }^{(4)}$. Devido ao seu alto poder de resolução, a IEF tornou-se a mais promissora e versátil metodologia para o estudo de sistemas polimórficos, incluindo-se as hemoglobinopatias, como também para a descoberta de novas variantes genéticas ${ }^{(19)}$.

Outras vantagens dessa metodologia seriam a possibilidade de utilizar somente uma pequena quantidade de eritrócitos ( $4 \mu \mathrm{l})$ e a aplicação de muitas amostras concomitantemente (até 80 amostras). Por outro lado, poder-se-ia obter o hemolisado tanto do sangue total, como de cartões de papel de filtro, como aqueles utilizados para o teste do pezinho. Essas adaptações representariam uma facilidade no caso da realização de triagens dessa patologia, tanto em adultos, quanto em crianças e recém-nascidos. 


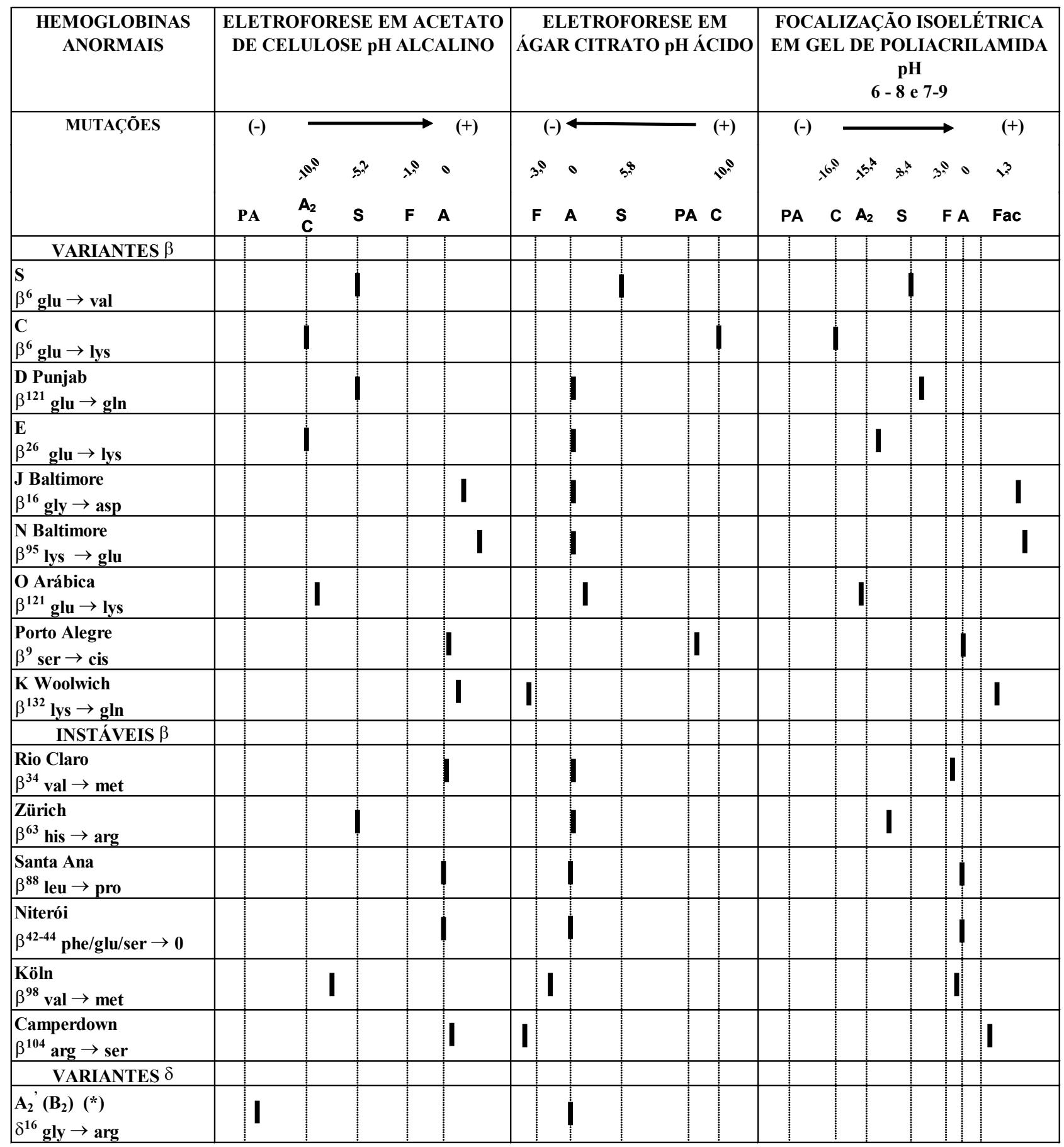

Figura 1

Com essas observações somadas a relatos da literatura e à experiência de outros laboratórios referentes às posições das hemoglobinas, foi possível o estabelecimento de quadros indicativos da posição de migração das hemoglobinopatias observadas na população brasileira, com a possibilidade de seu uso evidenciando a facilidade da utilização dessa técnica por diferentes laboratórios.

\section{Agradecimentos}

Agradecemos o suporte financeiro concedido pela Fundação Coordenação de Aperfeiçoamento de Pessoal de Nível Superior (CAPES) e pela Faculdade de Ciências Farmacêuticas da Universidade Estadual Paulista (FCF/ UNESP). 


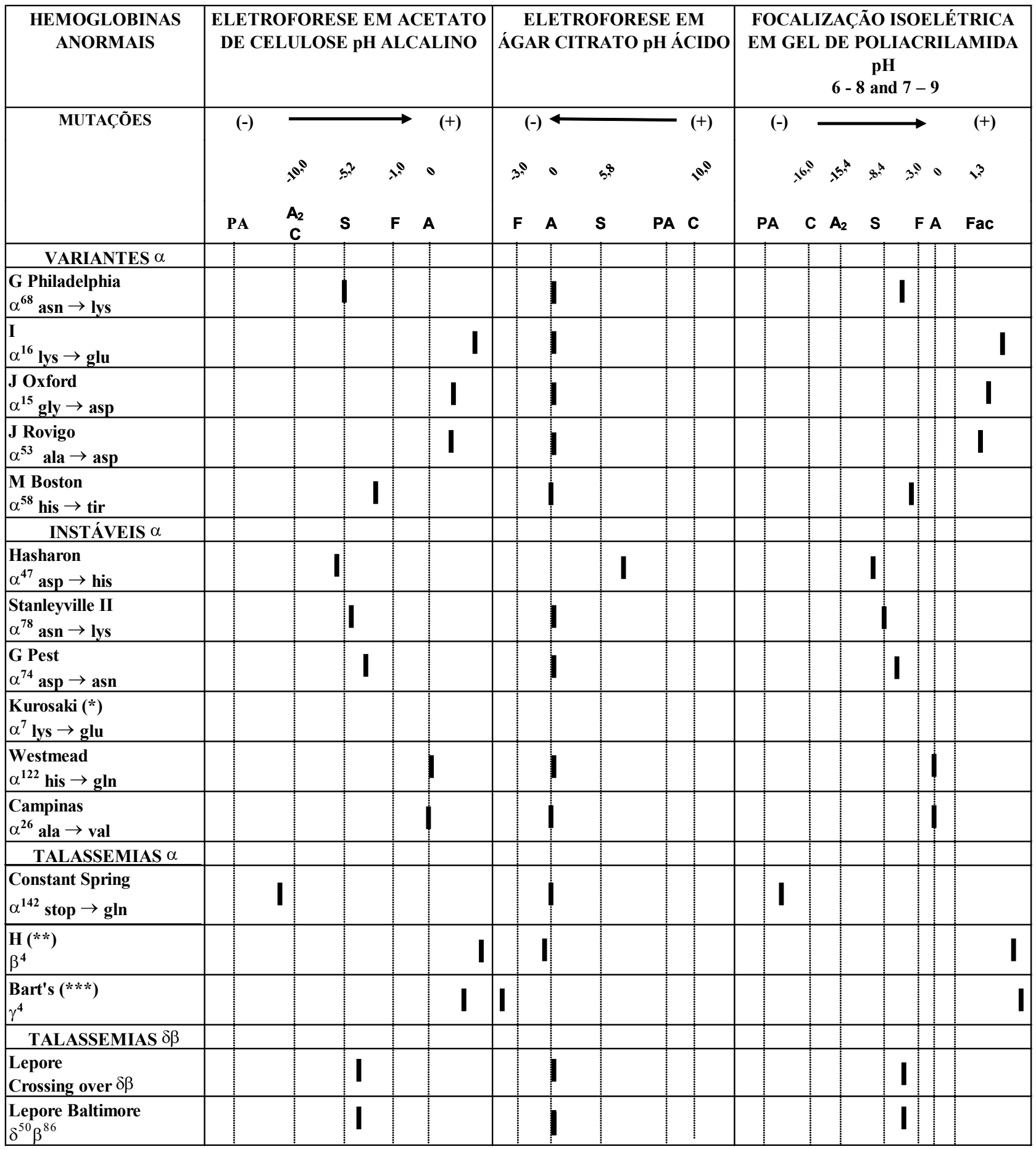

Figura 2

\section{Referências}

I.ALVARES FILHO, F. et al. Age and racial geographic distribution of S hemoglobin in Brazil. Sangre, v. 40, p. 97-102, 1995.

2. ARAUJO, J. T. Geographical distribution and incidence of hemoglobin variants in Brazil. In: Inter American Symposium on Hemoglobins, 1969 I; Caracas. Genetical, funcional and physical studies of hemoglobin. Proceedings Basel: Karger; 1971. p. 26-31.

3. BASSET, P. et al. Isoelectric focusing of human hemoglobin: its application to screening, to the characterization of 70 variants, and to the study of modified fractions of normal 
hemoglobin. Blood, v. 5I, n. 5, p. 97I-82, 1978.

4 BASSET, P.; BRACONNIER, F.; ROSA, J. An update on electrophoretic and chromatographic methods in the diagnosis of hemoglobinopathies. J Chromatogr, v. 227, p. 267-304, 1982.

5. BRASIL CHANNEL. Disponível em:<http://www.brasilchannel. com.br>. Acesso em: 18 nov, 2004.

6. COMPRI, M. B. Community-based programs for hereditary hemoglobinopathies in Brazilian high school students. Rev Saúde Pública, v. 30, p. 187-95, 1996.

7 DIEGUES Jr, M. Etnias e culturas no Brasil. Rio de Janeiro: Editora Biblioteca do Exército; 1980.

8. DIEGUES Jr, M. Imigração, urbanização e industrialização. Rio de Janeiro: Centro Brasileiro de Pesquisas Educacionais Instituto Nacional de Estudos Pedagógicos - MEC, 1964.

9. HONIG, G. R.; ADAMS III, J. G. Human hemoglobin genetics. New York: Springer; 1986.

I0. JENKINS, M. A.; RATNAIKE, S. Capillary isoelectric focusing of haemoglobin variants in the clinical laboratory. Clin Chim Acta, v. 289, p. 121-32, 1999.

I I. LEHMANN, H.; HUNTSMAN, R. G. Man's haemoglobins. Amsterdan: North-Holland Publishing Company; 1974.

12. MARENGO-ROWE,A.J. Rapid electrophoresis and quantitation of haemoglobin on cellulose acetate. Am J Clin Pathol, v. I8, p. 790-92, 1965.

13. MOREIRA, H.W. et al. Triagem das hemoglobinopatias por isoeletrofocalização.J Bras Patol, v. 35, p. | 4|-45, 1999.

14. NAOUM, P. C. et al. Hemoglobinas anormais no Brasil. Prevalência e distribuição geográfica. Rev Bras Patol Clin, v. 23, p. 68-79, 1987.
15. RAMALHO, A. S. et al. Hemoglobin screening: response of a brazilian community to optional programs. Cad Saúde Pública, v. 15, p. 59|-5, 1999.

16. RIGHETTI, P. G.; BOSSI,A. Isoelectric focusing in immobilized pH gradients: recent analytical and preparative developments. Anal Biochem, v. 247, p. I- 10, 1997.

17. RIGHETTI, P. G.; BOSSI, A. Isoelectric focusing of proteins and peptides in gel slabs and in capillaries. Anal Chim Acta, v. 372, p. I-19, 1998.

18. RIGHETTI, P. G. et al. Isoelectric focusing. In: HAMES, B. D; RICKWOOD, D. Gel electrophoresis of proteins a practical approach. Oxford: Oxford University Press; 1990. p. 149-216.

19. RIGHETTI, P. G. et al. Human globin chain separation by isoelectric focusing. J Biochem Biophys Meth, v. I, p. 45-57, 1979.

20. RIGHETTI, P. G. Analytical IEF. In: RIGHETTI, P. G. Isoelectric focusing: theory, methodology and applications. New York: Elsevier Biomedical Press; 1983. p. I 48-267.

21. SCHNEIDER, R. G. Electrophoretic methods in hemoglobin identifications. Hemoglobin, v. 4, p. 521-26, 1980.

22 SONATI, M. F. et al. Hereditary hemoglobinopathies in a population from southeast Brazil. Hemoglobin, v. 20, p. 175-9, 1996.

23 VELLA, F. Acid agar-gel electrophoresis of human hemoglobins. Am J Clin Pathol, v. 49, p. 440-50, 1968.

24 ZAGO, M.A. et al. Hereditary hemoglobin disorders in a Brazilian population. Hum Hered, v. 33, p. 125-9, 1983.

25 ZAGO, M.A.; FIGUEIREDO, M. S.; OGO, S. H. Bantu beta S cluster haplotype predominates among Brazilian blacks. Am J Phys Anthropol, v. 88, p. 295-8, 1992. 